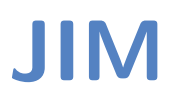

ISSN: 2183-0606

(CC BY 3.0)

Vol. 9, 2 (2021)

p. $21-38$

AM: May $/ 2021$

SM: Jul/2020

\title{
The Process of Social Innovation Scalability: What is the Role of Dynamic Capabilities?
}

\author{
Tatiane Martins Cruz Pirotti ${ }^{1}$, Cláudia Cristina Bitencourt ${ }^{2}$, Kadígia Faccin $^{3}$, and \\ Caroline Kretschmer ${ }^{4}$ \\ ${ }^{1}$ Unisinos University, Nilo Peçanha Street 1600 - 91330-002 - Porto Alegre, Brazil | \\ tatiane.martinsc@gmail.com \\ ${ }^{2}$ Unisinos University | claudiacb@unisinos.br \\ ${ }^{3}$ Unisinos University | kadigiaf@unisinos.br \\ ${ }^{4}$ Unisinos University | carolinekretschmer5@gmail.com
}

\begin{abstract}
Social innovations are important tools for minimizing or solving social problems. However, significant challenges remain in managing social innovation development for long-term survival and expanding its social impacts to generate scalability. This process can be supported by dynamic capabilities and their microprocesses. By conducting a single case study, we aim to contribute to the stream of research on management of social innovation that analyzes the ways in which dynamic capabilities can influence the scalability process of social innovation. Our contribution arises from generating an understanding of how and why dynamic capabilities influence the social innovation scalability process.
\end{abstract}

Keywords: Social Innovation; Dynamic Capabilities; Microfoundations; Scalability.

Cite paper as: Pirotti, T.M.C., Bitencourt, C.C., Faccin, K., Kretschmer, C., (2021). The Process of Social Innovation Scalability: What is the Role of Dynamic Capabilities?, Journal of Innovation Management, 9(2), 21-38.; DOI: https://doi.org/10.24840/2183-0606_009.002_0004

\section{Introduction}

Social innovation ( $\mathrm{SI}$ ) has attracted the interest of academics and public administrators because of its potential for creating solutions to various societal problems and generating positive effects (Perez et al., 2015). Have and Rubalcaba (2016) point to a significant increase in publications on the subject since the beginning of the 21st century. However, many doubts remain to be resolved (Montgomery, 2016), and there are still gaps in the SI literature, especially with regards to conceptual tools, which tend to be developed with a focus on market logic (Desmarchelier et al., 2018).

One criticism of $\mathrm{SI}$ is the lack of long-term programs and the lack of scalability of programs. In countries such as Brazil, SI is mainly related to specific projects, making it impossible to obtain effective results (Bolzan et al., 2017). The complexity of significant social change makes such change difficult to implement, and SI needs to be disseminated and diversified in order to be accepted by the affected communities and to ensure continuity and broad utilization and distribution to achieve longevity (Taylor, 1970).

Although progress can be observed in SI, the continuous generation of social problems means that the demand for solutions will continue to grow, increasing the gap between generated solutions and current needs. The complexity of such demands brings significant challenges, especially for management, since creating effective solutions requires more in-depth analysis (Gramescu, 2016). 
To achieve effective social impacts, SI must be scalable so that it can influence a larger audience in a more profound way (Gramescu, 2016). New methods for the development of SI are extremely important, and it is also necessary to identify areas in which problems are intensifying, existing models are flawed, or technological resources can help (Mulan et al., 2006).

Westley and Antadze (2010) indicate that one of the challenges of SI is finding ways to expand innovative solutions, extend their reach, and continually obtain funding sources to make offering such solutions sustainable. In addition to the ability to perceive problems that demand social solutions, the search for resources, adaptation to changes and transformation of the environment are essential factors for the scalability of SI. This understanding gives rise to the management logic of SI, which focuses mainly on diverse capabilities and processes that can contribute to the expansion of $\mathrm{SI}$, which is not a regular practice but has significant impacts (Westley and Antadze, 2010).

Agilely responding to the scenarios of change that have become dominant in recent years demands the creation of flexible mechanisms of differentiation and integration that allow for the development of so-called dynamic capabilities (DCs) to continuously orchestrate strategies and structures to perceive, train for, and use opportunities (Fellin and Powell, 2016).

According to Teece, Pisano, and Shuen (1997), DCs are an emerging and integrative approach to understanding new sources of advantages for organizations that operate in rapidly changing environments. The logic of DCs lies in developing in organizations the skills of perceiving and shaping opportunities, seizing them, and creating transformations. Therefore, we propose to associate these capabilities with $\mathrm{SI}$, whose objective is social transformation, which occurs by observing and understanding the social context, appropriating opportunities that can affect it and, finally, transforming this social context.

Microprocesses support DCs, and these can be managerial skills, processes, procedures, systems, and structures linked to each of these capabilities (Teece, 2007). The current economic and social context necessitates effective social transformations and their long-term maintenance. Thus, SI requires the development of these capabilities. Additionally, SI requires the skills and processes that support these capabilities for the survival and operation of scalability processes that culminate in social transformation.

We choose the theoretical lens of "dynamic capabilities" because this approach values innovation environments and rapid changes, which are understood as the context of SI. Moreover, for a better understanding of the studied phenomenon, the focus is on analyzing which microprocesses support each DC. Based on the concepts discussed, this research adopts, as a unit of analysis, an SI initiative maintained over 40 years with increasing social impacts based on DCs and their influence on the scalability process.

\section{Scalability of Social Innovation}

Innovative social initiatives that have had a strong local impact are expected to broaden their scale so that they can more profoundly influence a broader public. The search for scalability begins with realizing that the magnitude of the social problem is greater than the impact initially envisaged (Chand, 2012). In this way, the potential to promote social transformation is related to the scale capacity and social impacts generated by expansion. Therefore, for SI to create the desired social transformation, it must create sustainability and expansion strategies over the long term (Sigala, 2016).

However, scaling up requires, in addition to a skillful strategy, a broad and coherent view. To that end, the abilities to organize resources and to support the identification of crucial leverage 
positions and market opportunities become paramount. In addition, to convince investors, formal methods, such as ways to measure success, are needed (social investment returns) (Mulgan et al.,2006).

To reach the desired scale, aspects such as leadership capacity, experience, credibility and reputation, the quality of the product or service, and incremental innovations must be emphasized internally. Regarding the external environment, government support, philanthropy, community involvement, and the possibility of forming partnerships as a way of acquiring resources or skills should be prioritized (Silva et al., 2016).

Scalability is strongly related to the increase in the number of beneficiaries served, and the literature currently defines three types of scalability involving different approaches that may or may not occur simultaneously. For Moore et al. (2015), for example, scaling an SI in a way that can effectively impact the generative system of the social problem involves three types of scalability, all of which can interact to achieve the goal. The main definitions of these three types of scalability are as follows:

- Scaling deep: This term refers primarily to achieving significant changes in the relationships, cultural values, and beliefs of the actors involved in the process. The term is closely related to, for example, the place in which the SI is inserted, the transformations generated in a community, and the subjects that are related to the community (Moore et al., 2015).

- Scaling out: This term refers to efforts to increase the number of beneficiaries served or to cover a larger geographic area by expanding innovative ideas or products (Westley et al., 2014). It is mainly through this replication and dissemination that it becomes possible to impact more beneficiaries (Moore et al., 2015).

- Scaling up: This term refers to scalability that aims to extend the impact of an SI in a meaningful way. It is linked to the identification of opportunities and barriers on large institutional scales to change the system that created the social problem, which requires a reliable analysis of the context in which the $\mathrm{SI}$ is deployed and clear strategies for its execution. The purpose is to affect all of the people who are in need or to address the institutional roots of a problem (Westley et al., 2014).

It should be noted that these forms of scalability can occur simultaneously or can even drive one another. For example, Moore et al. (2015) identify a connection between scaling up and scaling out because, as change spreads geographically, the chance of influencing people at higher levels is greater. Likewise, at higher institutional levels, the chance of strengthening horizontal propagation is greater.

\section{Dynamic Capabilities and Microprocesses}

The development of DCs differentiates firms and is associated with highly entrepreneurial organizations (Teece, 2007); DC development is in high demand in markets with frequent changes. The concept is related to an organization's ability to integrate, build, and reconfigure its internal and external skills to handle rapidly changing environments. Additionally, DCs are related to complex processes that emerge from the dependencies of the organization's trajectory for the creation and capture of wealth (Teece, 2014; Teece et al., 1997).

According to Winter (2003), DCs are skills that generate expansion, change, or the creation of capabilities essential to the survival of a company. These capabilities support evolutionary aptitude through the creation, renewal and orchestration of specialized assets and resources (Pundziene and Teece, 2016). Accordingly, DCs are associated with change processes, whether in products, procedures, markets or scale. 
The dynamism of the market is an external factor for the existence of a DC; therefore, DCs can be developed in organizations that have differentiated responses to the demands that provide autonomy for individuals. Additionally, subunits create solutions and search for new opportunities that have mechanisms to convert information into a collective intellect (Felin and Powell, 2016). Teece (2007) states that, in addition to autonomy, the sustainability of DCs depends on the decentralization of processes and the proximity to the high management of technologies, production processes, and markets.

Moreover, DC implementation occurs through the aggregation of several competencies, which together form an essential process for the organization. To be effective, the main combinations of capabilities must be known. DCs are based on the organizational processes and routines articulated by the nonroutine action and mediation of managers (Teece, 2018). In this way, they are configured as capabilities that are difficult to replicate, as they are built based on the routines, culture, and idiosyncratic characteristics of managers throughout the development of the organization's history (Teece, 2014).

DC development is also associated with practice because as an organization begins to perform an activity and gains experience, its ability to perform similar activities in the future tends to improve (Zollo and Winter, 2002). According to Teece et al. (2016), organizations with superior DCs have highly entrepreneurial management teams and a robust organizational model.

Teece (2007) proposes dividing DCs into the categories of sensing, seizing, and transforming; these categories can be used for informational purposes and provide a framework for analyzing the development and orchestration of these resources. These categories are supported by managerial and organizational skills and allow the company to adjust to changes to take advantage of opportunities and evolve (Teece et al., 2016). The three categories are as follows.

- Sensing: This term refers to analytical systems and to individual capabilities to learn, perceive, filter, shape, and calibrate opportunities. According to Dong et al. (2016), such a capability generates a set of business opportunities that can be shaped and subsequently chosen to be harnessed.

- Seizing: This term relates to the structures, procedures, projects, and incentives to take advantage of opportunities. According to Teece et al. (2016), this capability concerns the implementation and execution of perceived opportunities, and there are ways to do this that preserve agility, including flexible arrangements for research, the adoption of open innovation processes, and others.

- Transforming: This term refers to the alignment and continuous realignment of specific tangible and intangible assets. Teece et al. (2016) point out that transformation in large organizations requires breaking away from conventional ways of thinking.

Teece et al. (2016) highlight the need for capabilities to identify, develop, and assess opportunities and threats concerning customer needs (sensing), in addition to the capability to mobilize resources to meet needs, seize opportunities, and continuously renew capabilities. These capabilities are needed to manage transformations and impact the abilities to innovate, adapt to changes and create favorable changes for customers, which are relate to the survival of organizations. Therefore, each dynamic capability is supported by microprocesses as explained below based on Teece (2007):

Microprocesses of sensing: This term refers to an internal process of R\&D and the selection of new technologies, processes for the use of external scientific and technological developments, processes to access suppliers and complementary innovation, and processes for identifying target market segments, changes in customer needs, and possible customer innovations.

Microprocesses of seizing: This term refers to delineating the business model and solutions 
for customers, selecting organizational boundaries for managing add-ons and controlling platforms, selecting decision-making protocols, and building loyalty and commitment.

Microprocesses of transforming: The term refers to decentralization, cospecialization, governance, and knowledge management.

DC microprocesses are the processes, procedures, organizational structures, rules for decision making and distinct disciplines that support the sensing, seizing and transforming capabilities that, although challenging to develop and implement, must be developed and applied simultaneously to build and maintain a competitive advantage (Teece, 2007).

Most of the microprocesses presented in the results of this case study emerged from the execution of the research, although some are related to the microprocesses previously presented by Teece (2007). As explained above, the purposes of SI are the creation of social transformation and social value, whereas DCs are the driving force of scalability (in terms of both the acquisition and management of resources). Therefore, the use of DCs as a theoretical lens can contribute to the development and scalability of SI by emphasizing three critical capabilities: sensing, seizing and transforming.

\section{Method}

Given the proposed objective and the characteristics of the object of study, we chose the qualitative approach in this study. The case study methodology aims to understand the dynamics present in a reality with unique characteristics in order to present theoretical relevance for the organizational context (Yin, 2017).

We selected the case using some previously defined criteria. We pursued Brazilian initiatives because of the urgency of increasing the scale capacity of SI in Brazil (Bolzan et al., 2017). We looked for institutions operating in at least two geographically distinct units that had been in operation for at least ten consecutive years and had served at least 10,000 beneficiaries. These criteria ensured the selection of a case that clearly had more than one form of scalability, that was not a transient initiative and that had a history that could be analyzed procedurally.

Data collection took place in 2017. Primary data were obtained through in-depth interviews and nonparticipant and participant observation. Sixteen interviews were conducted, with an average duration of 50 minutes each; these were recorded and later transcribed. Table 1 presents the list of respondents with the time and area in which they worked in the project.

Table I. List of respondents

\begin{tabular}{lc}
\hline Acting on the Project & Duration of involvement \\
\hline President of Honor & 41 years \\
\hline President & 10 years \\
\hline Superintendent Director & 20 years \\
\hline Project Manager & 13 years \\
\hline Expansion Coordinator & 08 years \\
\hline Regional Supervisor & 07 years \\
\hline Curator Advisor (Beneficiary in the 1990s) & 20 years \\
\hline Curator Advisor (Beneficiary in the 2000s) & 17 years \\
\hline Headquarters volunteer (Management) & 15 years \\
\hline
\end{tabular}




\begin{tabular}{lc}
\hline Acting on the Project & Duration of involvement \\
\hline Unit Articulator & 15 years \\
\hline Social Educator & 10 years \\
\hline Communication Analyst & 10 years \\
\hline Unit Articulator & 03 years \\
\hline Volunteer (Beneficiary in the 2010s) & 03 years \\
\hline Institutional Supporter (ERP Systems) & 02 years \\
\hline Institutional Supporter (Change Management) & 02 years \\
\hline
\end{tabular}

We chose the interviewees based on their position in the project, with the aim of obtaining perceptions from different actors (decision makers, performers, investors, etc.). In addition, the involvement of these actors and the duration of association with the SI were considered to obtain the historical narrative. Nonparticipant observation occurred through visits and watching events, while participant observation occurred during eight weekly meetings when one researcher performed volunteer work in one of the units. This provided an opportunity to experience $\mathrm{SI}$ in its essence and to contact the beneficiaries during the formation process.

Secondary data collection was conducted through a review of documents provided by managers, research on sites and partner organizations that had relevant publications, and a search for related works and videos published on social media.

We used the process data approach to understand the context and various events that influenced SI scalability and to detect the patterns and sequence of such events based on the perception of individuals (Langley, 1999).

For Langley (1999), an event is a conceptual entity, and it is the primary focus of process data analysis. Events can involve many levels and units of analysis without well-defined boundaries and vary in time, accuracy, duration, and relevance.

We used the narrative strategy to contextualize and retrieve the story, mainly from the interviews conducted. We triangulated the information collected with secondary data for greater reliability.

Then, we used the visual map strategy, which provides a graphic representation of the phenomenon that covers a large amount of information in a limited space and contemplates precedence, parallel processes, and the passage of time. (LANGLEY, 1999). As the trajectory of the case studied occurred over a long period of time and involved various events and individuals, this strategy facilitated the synthesis of the scalability process.

For data analysis, first, we used the software ATLAS.ti to organize the data and identify the events that occurred in the project's trajectory that gave rise to the different types of scalability. After using this software to code the data, we group the codes into categories according to the three types of scalability found in the literature: scaling up, scaling out and scaling deep.

Then, we identified and created codes for the DC microprocesses that emerged from the field by considering the context of the SI, which differs in some ways from the competitive environment considered by Teece (2007) and other related authors. Subsequently, the linked excerpts were associated with each of the three DCs determined by Teece (2007): sensing, seizing, and transforming.

In the next step, we cross these microprocesses of DCs with the events that showed the three types of SI scalability. We determined whether such microprocesses could have impacted SI scalability. From this analysis, we developed a visual map that identified in each phase the 


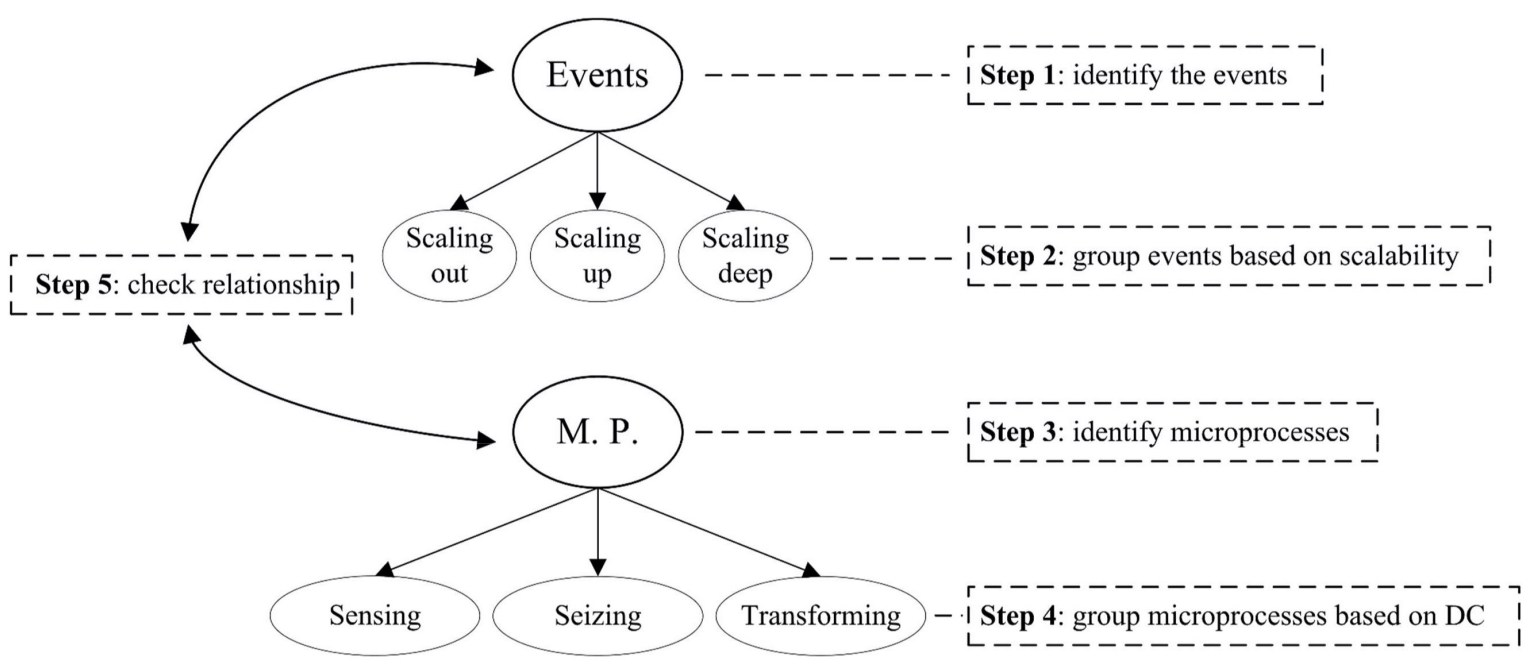

Figure 1. Data Analysis Process

types of scalability and the DC microprocesses identified. This map is presented in Figure 2 and is discussed in the Results and Discussion section.

\section{Results and Discussion}

This SI initiative is viewed as a pioneer in Brazil because it engages companies, communities and volunteers with the aim of addressing the problem of the social vulnerability of young people at the stage when they must prepare for adulthood.

The search for SI continuity, the creation of mechanisms for updating and governance, and the lack of political ties provide an example of society itself creating alternatives for social transformation to happen. Thus, in this section, we seek to contextualize and narrate how the SI occurred and which events impacts the scaling process of the Fish Project ("Projeto Pescar" in Portuguese).

\subsection{The case}

We selected the Fish Project, which has had significant impacts on social transformation in Brazil and abroad (with a presence in five countries), with over 30,000 young graduates, by achieving high employability rates $(92.1 \%)$ for graduates. The initiative stands out for its expansion and survival for over 40 years and because the adopted management model differentiates it from other social institutions.

Currently, the network comprises 100 investors and supporters and more than 2,000 volunteers. The primary objective of this SI initiative is the social transformation of young people in situations of social vulnerability through their preparation and empowerment to enter the labor market. From its conception, the objective of the SI has been to satisfy needs that were previously unmet by existing systems, whether public or private, by using the definition of SI proposed by Moulaert et al. (2007).

The Fish Project promotes quality of life through its work methodology, which favors the professional and citizen education of socially vulnerable young people. It encourages the engagement of various stakeholders, such as companies, partner institutions, volunteers, employee contractors, and the users themselves. It is an SI that acts in a gap that is seen as severe and where there is a 


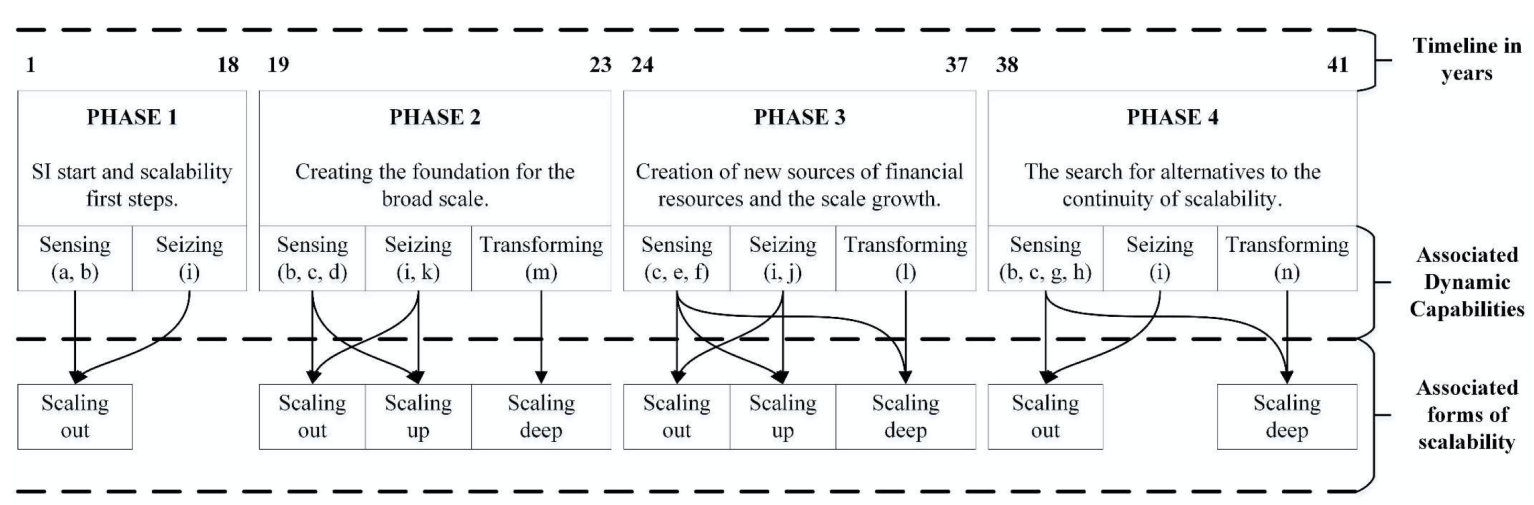

Figure 2. Scalability Procedural Map

deficit of SIs: the complicated process of transition from adolescence to adulthood.

Mulgan et al. (2006) point to the urgent need to create SI initiatives that support young people in the orientation toward and successful pursuit of a career, relationships, and more stable lifestyles. By proposing a socioprofessional formation, the researched case manages to meet these demands with the practical results of social transformation.

\subsection{The story of scalability}

The action of an entrepreneur started the SI initiative, but we noticed that scalability essentially occurred through the adoption of partnerships and the formation of networks. DCs were the basis for these processes. According to Mulgan (2006), this change from an entrepreneur leading the beginning of $\mathrm{SI}$ in an ideal way to adding other actors to its cause along the trajectory is a frequent phenomenon.

This SI initiative developed several strategies to attract potential investors and partners. Some of these included the creation of a foundation and agreements with public authorities and private institutions, which, with the raising of funds, increased the number of people affected.

After the historical survey, we divided the case into four main stages of scalability. The periods were established according to the occurrence of events considered to be decisive for scalability. In the visual map, we demonstrate the scalability process of SI over time. In each phase, it is possible to see which DC and the associated microprocesses (represented by the letters "a" to " $n$ " in section 5.3 and its subsections) impacted the generation of each type of scale.

The first phase (1976 to 1995) was the conception and development of the SI and was marked by the beginning of the scalability process. It took 12 years of work and attempts for a second investor to adopt the SI, and from then on, others began to follow suit. It was a period of designing the structure and getting to know the possibilities of acting better. The last event in this phase was a trip to the United States to perform a benchmark with the reference institutions of this country.

The second phase (mid-1995 to 2000) was the first moment of scalability growth. This period began with the creation of a foundation that served to organize the process of scalability and the form of SI itself and ended with the foundation's first strategic planning and adoption of governance practices, which aimed at transparent action to connect more partners.

The third phase (mid-2000 to 2013) was the scalability consolidation phase, which was identified as the most significant for scalability, with an increase in the number of beneficiaries and places of operation. It started with the first significant contribution from a foreign investor 
and ended with the implementation of the first unit outside the Americas.

Finally, the fourth and current phase (since 2014) is the adaptation phase, which aims to maintain scalability. This phase began with the establishment of a scenario of economic crisis and continued with the implementation of change management processes. The challenge at this stage is the creation of strategies directed at adapting to new economic scenarios and partner needs. In this phase, we emphasize the cost reductions achieved through partnerships and the adoption of technological tools to optimize processes.

By preparing young people to enter the labor market and to organize their lives in a way that positively impacts their future, their family, and their community, this SI initiative can protect young people from the previously mentioned adversities.

When the goal is achieved, the beneficiary can move from an initial situation of vulnerability to the role of a citizen who is ready to seek alternative livelihoods, whether through formal work or entrepreneurship, to thus achieve social transformation. From the beginning of the process, the search to improve the quality of life of the project's beneficiaries often impacts their family members and even the community, which generates results that go beyond the frontiers of SI.

These microprocesses supported the generation of scaling out, scaling up and scaling deep. This led to a change from an initial service situation for a group of 15 beneficiaries in a single organization to the current situation of more than 30,000 young people involved, in different locations, with the participation of supporters and investors and the formation of networks.

\subsection{Dynamic capabilities in the context of SI scalability}

Although it is dynamic and complex, the SI context differs in some respects from that initially proposed by Teece (2007) regarding the identification of DCs. The main difference is competitiveness, since when considering the business context, one of the motivators of DCs is the generation of a competitive advantage.

In the SI context, the focus is on the solution to the social problem; therefore, the context is more focused on cooperation than profit, such as in the SI object of this study. In this way, the microprocesses identified in the data collection are, in many cases, different from those previously established by Teece (2007).

The data analysis indicates that the creation of a partner network and the accumulation of supporters contribute to several aspects of the development of SI DCs and to their survival and scalability, which attributes a particular character to this type of innovation: the collective construction of DCs. DC microprocesses do not depend exclusively on SI management, although their performance is crucial. Many other actors who are present in the network may be important and diverse in this process, especially when thinking of scenarios in which the $\mathrm{SI}$ is geographically spread out.

To better elucidate the findings of the research, the following is a summary of the main microprocesses evidenced from the case study of the Fish Project according to the DCs to which they are linked.

\section{Sensing}

The capability to detect opportunities is perceived in this study as fundamental to the SI scalability process since the detection of opportunities and threats enables the SI to perceive the needs or possibilities for change and to update over time to meet the demands of the interested public. Next, we list the main microprocesses identified and associated with the dynamic sensing capability. 


\section{Sensing $x$ scaling out}

a) Identification of the target public: The identification of the SI beneficiaries occurred before the implementation of the SI since the idea that gave rise to it was the need to serve a specific group: young people in situations of social vulnerability. This group comprises a large population that is likely to benefit, which encouraged the $\mathrm{SI}$ to continue to pursue this service. This factor is one of the great motivators in the search for all types of scalability, especially scaling out.

b) Research for access to innovation in reference and benchmarking institutions: The search for external quality standards has become fundamental for the development of the SI. In the early 1990s, when Brazil did not yet have many models of foundations and institutes, managers surveyed American social institutions that would provide alternatives to shape SI management based on successful references. Although such a survey may impact all types of scalability, the empirical evidence, in this case, mainly points to scaling out.

According to the interviewees, the search for reference models and exchanges with other institutions continues to be a practice that facilitates the perception of improvement points, innovation possibilities, and efficiency gains.

c) Processes to source and raise funds and financial support for continuity and improvement: Public or private institutions are constantly sought that provide support to improve processes. Additionally, the free support of specialized consultancies is continuously sought and ensures both essential savings and continued updates. Although this microprocess is also associated with retention, without research and a search for opportunities, the capture of savings and support does not occur.

Gains in efficiency-through the adoption of new technologies, improvements in work methodology and investments in activities for scalability-support the survival of the SI, which affects scaling out.

\section{Sensing $x$ scaling up}

d) Processes to identify target market segments: When researching new forms of performance and survival, the researched SI planned performance changes based on a desire to grow in a way that impacts the system, which also reflects the scaling up process.

e) Update and influence other actors by participating in a deliberative council: Over the years, the SI prepared some key actors for representation on deliberative councils. This action allows for the broad perception of the national context and trends and the opportunity to disseminate ideas, which facilitates the process of scaling up.

\section{Sensing $x$ scaling deep}

f) Processes to identify partners' needs: This microprocess, in addition to influencing the scaling out process, also affects the scaling deep process by enriching the SI through the cultural and territorial characteristics of its partners.

g) Reading of contexts and customized approaches: The understanding of different contexts improves the delivery capacity by making it possible to adapt to these contexts and by facilitating the dissemination of various approaches through solutions and supports that are customized to each reality, which facilitates the process of scaling deep.

h) Practices for the exchange and reception of information and knowledge, idea capture and the follow-up of SI execution: The replication of good practices in different units can affect both scaling out and scaling deep by individually strengthening each of these units. Additionally, the ideas that are captured help optimize the processes that impact SI sustainability. 


\section{Seizing}

The capability to seize (Teece, 2007) is observed as a success factor for the implementation and support of the opportunities perceived by the SI, which provides the conditions to structure, implement and maintain projects and programs to improve the SI, optimize processes and update the work methodology.

\section{Seizing $x$ scaling out}

i) Adaptation and delineation of the business model, solutions for partners, and new forms of fundraising: Adaptations to meet the needs of partners facilitated the adoption of the SI by stakeholders through greater adherence to their reality. Some examples of these actions are the creation of the Fish Project Foundation exclusively to support the execution of the SI in other organizations, the certification for compliance with the compulsory professional learning law in Brazil for companies, and the fulfillment of all legal factors for recognition by public bodies in all instances as relevant social work.

j) Processes to develop new sources of resources and to expand and create new partnerships and action formats: New types of partnerships and new ways to raise funds are developed, for instance, through partnerships with government institutions, a group of maintainers, and fundraising via donations, which are recognized in the research as being essential for the survival and longevity of the SI.

In recent years, the promotion of the adoption of new models of action has begun to be disseminated by the SI. The creation of consortia among several organizations has been the main model, but units have also been created in partnership with communities, NGOs, and religious institutions, among others. This approach considerably broadens the range of partners.

k) Processes of adaptation to external needs: Adaptation to the demands that are not controllable by the $\mathrm{SI}$ is essential to survive and affects scalability, especially for the maintenance of the beneficiaries involved. New opportunities can be used, and difficulties can be overcome to strengthen the SI for processes such as scaling out.

\section{Seizing $x$ scaling up}

i) Adaptation and delineation of the business model, solutions for partners, and new forms of fundraising: The adoption of practices linked to the institutionalization of SI and the changes in the "business model" generate recognition and can impact different levels and actors in society.

\section{Transforming}

The transforming capability makes it possible to adapt the SI to new scenarios to keep it current. Additionally, in the context of SI, this DC may be one of the results observed in the environment in which the case $\mathrm{SI}$ is inserted. The social transformation generated in the beneficiaries and the transformations in the environment allow this DC to surpass the borders of the SI while also reaching externally.

\section{Transforming $x$ scaling deep}

1) Mechanisms for social transformation and beneficiary protagonism: By adopting practices to transform young people and make them the protagonists of their choices and actions, the SI succeeds in extracting them from the position of beneficiary and helps them understand how to change the course of their lives on their own. One of the great examples of this result is the creation of a curriculum where $60 \%$ of the time focuses on aspects of personal development and citizenship. In recent decades, recognition has been greater from graduates, who often return as 
volunteers, and from entrepreneurs and supporters. In this way, the transforming capability is used in both an institutional way and beyond the limits of the SI so that it flows through the results that impact the target audience, which is one way to generate scaling deep.

$m$ ) Governance: The adoption of governance practices such as the creation of a consulting board that aims to guarantee SI transparency and longevity was a significant transformation in this case. The adoption of these practices strengthened the Sl's identity and culture of integrity.

n) Knowledge management: The mapping, review and identification of processes and key actors facilitated support to the units and the dissemination and application of knowledge among all involved. This process was identified as important for understanding and optimizing processes, reducing costs, and aligning the execution of best practices among several units.

When addressing a geographically dispersed SI, knowledge management still supports the identification of particularities and the execution of the purpose of $\mathrm{SI}$ in all units. Although knowledge management may affect the other forms of scalability due to possible efficiency gains, this research shows the impact of knowledge management on scaling deep.

\section{Synthesis of the DC microprocesses and the SI scalability process}

When analyzing the identified microprocesses for the SI, a higher incidence of sensing and a more significant connection between these and scaling out were observed. However, in some contexts, they also connected to scaling up and scaling deep, which was perceived much less frequently, as shown in the scalability process map in Figure 2. This result is associated with the complexity of each of the approaches employed since scaling up aims to impact the system that generates the social problem or its deeper roots, which requires a significant investment of resources and energy. Scaling deep aims at a more locally intensive impact, which requires not only the performance of the SI executing agencies but also the engagement of all stakeholders, while scaling out is linked more to the performance of the people directly involved in the SI.

However, scaling out can also have a greater urgency since, by creating more units in more territories, strength can be gained to impact the entire system and to change the reality of each of the communities that receive the SI. In this way, scaling out can facilitate the occurrence of other types of scalability.

Some of the events that are most relevant to the scalability process are associated with the microprocesses of seizing because they refer to the action performed or the deployment or adoption of a method. However, a deeper analysis of the research reveals that all the events of a phase change are born of or follow some sensing microprocess.

The creation of the SI can be cited as an example of this connection with sensing since the SI started from the perception of a social problem and an idea that could bring about a solution. Subsequently, the creation of the foundation to scale up the SI was formulated based on previous research in the reference institutions.

As mentioned, sensing microprocesses occur more often than the other DCs, and although the DCs do not necessarily occur in sequence, they do move in iteration with one another (Teece, 2007). For the Fish Project, perception of the environment, context, opportunities, and threats is necessary for the survival of the SI and impacts the incidence of the other DCs, which are executed based on these perceptions.

The microprocesses change according to the phase experienced by the $\mathrm{SI}$ as new demands arise, whether due to the external environment or to internal needs, and it is possible to observe the creation of new microprocesses throughout the history of this SI. For Felin and Powell (2016), it is essential that organizations not only improve existing resources but also constantly create 
new resources that can meet the demands perceived in the environment.

Although autonomy and the constant search for information in the external environment are fundamental for the existence of DCs, a certain level of organization and structuring is necessary for ideas to be put into practice and for projects to get off the ground (Felin and Powell, 2016). Although people have ways of capturing information and ideas in a way that is not strongly hierarchical, one of the highlights of this case is that there is a structure to address and manage the implementation.

The type of microprocess employed is related to the DC required at the time. In response to an economic crisis, the capability for sensing is in greater demand at first, since it becomes necessary to perceive the changes that are taking place in the environment and to try to shape opportunities from them (Teece, 2007). Thus, established practices are linked more to identifying opportunities and threats, reading contexts (which impacts new partnership and action formats) and developing processes for capturing and sensitizing new contacts.

Such microprocesses are usually established by SI management definitions using the experiences and knowledge of the actors involved at various levels, whether they are SI performers in localities, directors, unit managers, supporters, or partners. Therefore, the involvement of many people acting in several segments facilitates the creation of new microprocesses and promotes scalability.

The analysis of the process of scalability during the four decades of the Fish Project shows that initially, the actions were provoked by the SI. Additionally, although scaling occurred more slowly in the first decades, this period allowed managers to acquire experiences and build a knowledge base. More recently, due to the dynamism of the market and the increase in SI complexity, considering the market's significant growth, many of the actions have been responses to the environment.

\section{Final Considerations}

The present study began with a concern about the difficulties of the appropriation, perpetuation, and sustainability of SI. We then considered the possibility of (re)thinking the DCs in this environment as a way of helping to minimize or resolve such problems based on the nature of the DC approach and the presented problem (which is clearly a management-scalability problem).

Several main events led the SI to the current stage of scalability. Notable events include the creation of a foundation to support scalability; the realization of strategic planning to identify opportunities and threats and to devise strategies; the establishment of partnerships with larger institutions that enabled the acquisition of significant financial contributions, which boosted the scaling out action with the opening of new units; and the use of legal issues to benefit the SI.

In addition, the scalability process is not linear; the types and quantities of events and the periods of their occurrence vary. The SI needed to undergo an initial process of consolidation and maturation, although the focus on scaling up was present from the beginning. Mulgan et al. (2006) point out that an SI may need decades until the necessary environmental conditions are created for its scalability. Then, it is essential to persuade stakeholders and engage actors who can support the process.

Scaling of the case SI required a significant period to begin, as it took twelve years to open a second unit due to both external environmental factors (the interests of other entrepreneurs and because the culture of social responsibility is not broadly shared) and internal organizational factors (a lack of structure to manage and replicate the idea). Persevering in the idea of scaling has allowed the SI to overcome some of the possible organizational challenges by preparing it to deliver services that are meaningful to not only beneficiaries but also supporters.

Moreover, scalability depends on innumerable variables, both internal, which can be more 
easily manipulated by SI management, and external, which require preparation or adaptation actions. An example of the internal aspects is the preparation of the SI to offer a social project that is easy to implement, that complies with all the legal and bureaucratic dimensions, and that facilitates adoption, especially since the largest group of public supporters comprises entrepreneurs who need some guarantees to link their brands to an SI.

Desmarchelier et al. (2020) warn that knowledge of the local community, including its "modus operandum", is a key factor for the success of an SI. In this way, we observed that adapting to the reality of each community where there is an SI unit has become very important for the SI's continuity and is directly linked to the processes of scaling deep.

One of the critical factors for SI scalability is an enabling environment for growth (Mulan et al., 2006). In the case studied, the Brazilian context in which the SI started and expanded was favorable for growth due to both the number of families in situations of vulnerability and the lack of public or private initiatives to solve such problems.

Another factor is the search for the creation of a diversified network of partners. This is one of the constant efforts that the SI researched, which positively contributed to the process of scalability, to the access to and mobilization of resources, and to the access to knowledge, in accordance with Sigala (2016). Desmarchelier et al. (2018) also emphasize the importance of SI networks as a way to create effective solutions to "perverse" social problems (including social vulnerability and a lack of access to education) to support what public management is unable to address, which was also observed in this research.

Thus, a single strategy cannot be adopted for the scalability process. It is necessary to perceive market opportunities, threats, and potential investors, take advantage of possibilities, and adapt to suitability and service. These are the reasons that DCs are so important.

In this case, survival is a form of scalability, since each year, thousands of new beneficiaries are served. In this way, as the SI continues to serve approximately 2,000 young people annually, all types of scalability can be impacted. When the social transformation generated is more significant, more people move from being beneficiaries to being advocates for the dissemination of the idea, which influences their communities, public institutions, and families.

As a theoretical contribution, this study advances the understanding of how and why DCs influence the scalability process. DCs are a complex subject. DCs are exploited and have recognizable impacts in competitive environments, which are different from the usually collaborative SI context. However, this in-depth study emphasizes the importance of DCs for SI, as they were shown to contribute positively to the scalability process, even in a social context.

Based on a greater understanding of how the scalability process can occur and what practices (microprocesses) can affect it, we hope to contribute not only to the guidance of SI projects, especially the aspects of management and the development of solutions to support scalability, but also to the creation of public policies that support the development of more sustainable and more impactful SI.

A potential limitation of this study is the use of retrospective interviews. Specifically, we described processes experienced up to four decades ago based on existing memories. To minimize this limitation, we conducted interviews looking for redundancy and adopted data triangulation.

Among future research options, a multiple case study can analyze the occurrence of the DCs identified in SI initiatives of different segments. The study of the networks for SI scalability could also be deepened through new research. Although some authors consider the formation of networks necessary for scalability, no study centrally addresses this aspect. The case study reveals the opportunity to deepen the understanding of the role of networks (organizational and people) in the scalability process. One suggestion for future studies is to conduct qualitative research 
focused on scaling deep by analyzing the units and verifying both the social impacts generated in the community in which the SI is inserted and the cultural aspects of each SI.

\section{References}

Bolzan, L. M., Bitencourt, C. C., \& Martins, B. V. (2017). Escalabilidade de Inovação Social: Uma Meta-Análise. Simpósio Internacional de Gestão de Projetos, Inovação e Sustentabilidade, n. Anais do VI SINGEP-São Paulo-SP-Brasil-13 e, 1-16.

Chand, V. S. (2012). Book Review: Scaling Social Impact: New Thinking. The Journal of Entrepreneurship, 21(1), 157-163. https://doi.org/10.1177/097135571102100107

Desmarchelier, B., Djellal, F., \& Gallouj, F. (2018). Services in innovation networks and innovation networks in services: from traditional innovation networks (TINs) to public service innovation networks (PSINs). 28th RESER Conference, "Services in the age of contested globalization", Sep 2018, Gotheborg, Sweden. halshs-01934282

Desmarchelier, B., Djellal, F., \& Gallouj, F. (2020). Mapping social innovation networks: Knowledge intensive social services as systems builders. Technological Forecasting and Social Change, 157 (May), 120068. https://doi.org/10.1016/j.techfore.2020.120068

Dong, A., Garbuio, M., \& Lovallo, D. (2016). Generative sensing: A design perspective on the microfoundations of sensing capabilities. California Management Review, 58(4), 97-117. https://doi.org/10.1525/cmr.2016.58.4.97

Eisenhardt, K. M., \& Martin, J. A. (2000). Dynamic capabilities: what are they?. Strategic management journal, 21(10-11), 1105-1121. https://doi.org/10.1002/1097-0266(200010/11)21:10/11<1105::AIDSMJ133>3.0.CO;2-E

Felin, T., \& Powell, T. C. (2016). Designing organizations for dynamic capabilities. California Management Review, 58(4), 78-96. https://doi.org/10.1525/cmr.2016.58.4.78

Gramescu, L. (2016). Scaling social innovation in Europe: An overview of social enterprise readiness. Procedia-Social and Behavioral Sciences, 221, 218-225. https://doi.org/10.1016/j. sbspro.2016.05.109

Have, R. P. V., \& Rubalcaba, L. (2016) Social innovation research: An emerging area of innovation studies? Research Policy, 45 (9), 1923-1935. https://doi.org/10.1016/j.respol.2016.06.010.

Howaldt, J., Domanski, D., \& Kaletka, C. (2016). Social innovation: Towards a new innovation paradigm. RAM. Revista de Administração Mackenzie, 17(6), 20-44. https://doi.org/10.1590/ 1678-69712016/administracao.v17n6p20-44

Langley, A. (1999). Strategies for theorizing from process data. Academy of Management review, 24(4), 691-710. https://doi.org/10.5465/amr.1999.2553248

Montgomery, T. (2016). Are social innovation paradigms incommensurable?. Voluntas: International Journal of Voluntary and Nonprofit Organizations, 27(4), 1979-2000. https://doi.org/10. $1007 /$ s11266-016-9688-1

Moore, M. L., Riddell, D., \& Vocisano, D. (2015). Scaling out, scaling up, scaling deep: strategies of non-profits in advancing systemic social innovation. Journal of Corporate Citizenship, (58), 67-84. https://doi.org/10.9774/GLEAF.4700.2015.ju.00009

Moulaert, F., Martinelli, F., González, S., \& Swyngedouw, E. (2007). Introduction: social 
innovation and governance in European cities: urban development between path dependency and radical innovation. European Urban and Regional Studies, 14(3), 195-209. https://doi.org/10. $1177 / 0969776407077737$

Mulgan, G. (2006). The process of social innovation. Innovations: technology, governance, globalization, 1(2), 145-162. https://doi.org/10.1162/itgg.2006.1.2.145

Mulgan, G., Wilkie, N., Tucker, S., Ali, R., Davis, F., \& Liptrot, T. (2006). Social Silicon Valleys: A manifesto for social innovation. Young Foundation: Spring, pp. 01-67.

Perez, M. J.S., Álvarez-González, L. I., \& Rey-García, M. (2015). How to encourage social innovations: a resource-based approach. The Service Industries Journal, 35(7-8), 430-447. https: //doi.org/10.1080/02642069.2015.1015517

Pol, E., \& Ville, S. (2009). Social innovation: Buzz word or enduring term?. The Journal of socio-economics, 38(6), 878-885. https://doi.org/10.1016/j.socec.2009.02.011

Pundziene, A., \& Teece, D. J. (2016). New applications of dynamic capability research. Baltic Journal of Management, 11(3), https://doi.org/10.1108/BJM-05-2016-0103

Sigala, M. (2016). Learning with the market: A market approach and framework for developing social entrepreneurship in tourism and hospitality. International Journal of Contemporary Hospitality Management, 28(6), 1245-1286. https://doi.org/10.1108/IJCHM-06-2014-0285

Silva, R. L. M., Takahashi, A. R. W., \& Segatto, A. P. (2016). Scaling up social innovation: a meta-synthesis. RAM. Revista de Administração Mackenzie, 17(6), 134-163. https://doi.org/10. 1590/1678-69712016/administracao.v17n6p134-163

Taylor, J. B. (1970). Introducing social innovation. The Journal of Applied Behavioral Science, 6(1), 69-77. https://doi.org/10.1177/002188637000600104

Teece, D. J. (2007). Explicating dynamic capabilities: the nature and microfoundations of (sustainable) enterprise performance. Strategic management journal, 28(13), 1319-1350. https: //doi.org/10.1002/smj.640

Teece, D. J. (2014). The foundations of enterprise performance: Dynamic and ordinary capabilities in an (economic) theory of firms. Academy of management perspectives, 28(4), 328-352.

Teece, D. J. (2018). Business models and dynamic capabilities. Long range planning, 51(1), 40-49.

Teece, D. J., Peteraf, M., \& Leih, S. (2016). Dynamic capabilities and organizational agility: Risk, uncertainty, and strategy in the innovation economy. California Management Review, 58(4), 13-35. https: //doi.org/10.1525/cmr.2016.58.4.13

Teece, D. J., Pisano, G., \& Shuen, A. (1997). Dynamic capabilities and strategic management. Strategic management journal, 18(7), 509-533.

Westley, F., \& Antadze, N. (2010). Making a difference: Strategies for scaling social innovation for greater impact. Innovation Journal, 15(2), 1-19

Westley, F., Antadze, N., Riddell, D. J., Robinson, K., \& Geobey, S. (2014). Five configurations for scaling up social innovation: Case examples of nonprofit organizations from Canada. The Journal of Applied Behavioral Science, 50(3), 234-260. https://doi.org/10.1177/0021886314532945

Winter, S. G. (2003). Understanding dynamic capabilities. Strategic management journal, 24(10), 991-995. https://doi.org/10.1002/smj.318 
Pirotti, Bitencourt, Faccin, Kretschmer

Yin, R. K. (2017). Case study research and applications: design and methods. Sage publications.

Zollo, M., \& Winter, S. G. (2002). Deliberate learning and the evolution of dynamic capabilities. Organization science, 13(3), 339-351. https://doi.org/10.1287/orsc.13.3.339.2780 


\section{Biographies}

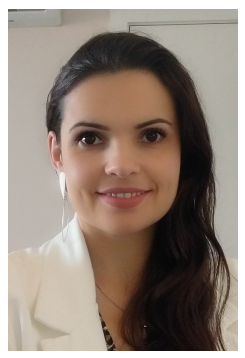

Tatiane Martins Cruz Pirotti. Tatiane Martins Cruz Pirotti is Master in Business Administration from Unisinos University, Brazil. Bachelor of Business Administration from Unisinos University - Brazil and Specialist in Organizational Psychology from Fadergs - Laureate Universities Brazil. She is a business consultant in the areas of corporate social responsibility and people management. Tatiane's research focuses on social innovation and business strategy. CRediT Statement: Conceptualization, Investigation, Formal Analysis, Methodology and Writing

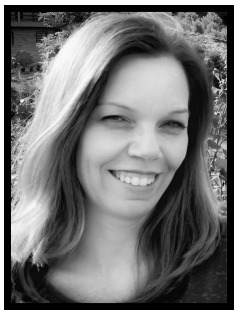

Cláudia Cristina Bitencourt. Claudia Bitencourt is Ph.D. in Business Administration from UFRGS, Brazil. Currently, she is a full professor and researcher at Unisinos Graduate Program in Business; Dean of the Unisinos Business School; Scientific director of ANPAD (Brazilian Academy of Management); Ambassador of the Human Resources Division of the Academy of Management; Member of the International Councils AACSB/LATAM and IAJBS. She was a Fulbright scholar at Thunderbird School of Global Management and visiting researcher at the following institutions: TU Dortmund, University of Stavanger, University of Texas-Pan American, University of Lisbon, The University of Queensland. Claudia's research focuses on social innovation, organizational learning, and capabilities.

CRediT Statement: Supervision, Investigation and Writing Review

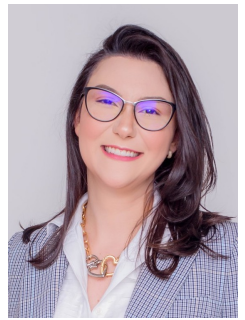

Kadígia Faccin. Kadígia Faccin is professor at Unisinos University. Her main research interests are: Interorganizational Relationships, Collaborative Innovation, Interorganizational Knowledge Management, and Innovation Ecosystems. She is the coordinator of the Research Group in Innovation Ecosystems (Ecohubi). She is also director of the special interest group on innovation and entrepreneurship at the National Association of Post-Graduation in Brazil (ANPAD). She is member of the scientific committee of Brazilian journals and conferences, and member of the Scientific Committee of the European Conference on Knowledge Management (ECKM). She has published a book on research techniques for scientific initiation and articles in academic journals, such as Journal of Business Research, Growth and Change, Creativity and Innovation Management, and Journal of Knowledge Management.

CRediT Statement: Supervision, Metodology and Writing Review

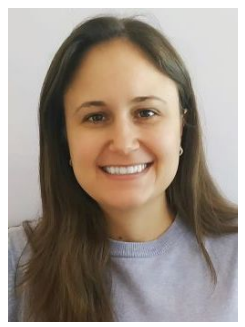

Caroline Kretschmer. Caroline Kretschmer obtained her $\mathrm{PhD}$ at the Unisinos University. Her main research interests are strategy, internationalization, entrepreneurship, and small business management.

CRediT Statement: Data Curation, Conceptualization and Investigation 